\title{
The Relationship among Chronic Disease, Feeling-for-Their-Age, Sleep Quality, Health-Related Quality of Life and Activities of Daily Living of Community-Dwelling Persons over 55 Years of Age
}

\author{
Hiroko Sugimoto', Tetsuya Tanioka², Yuko Yasuhara², Arisa Kurokawa1, \\ Miki Sato ${ }^{3}$, Kazuhiro Ozawa ${ }^{4}$, Rozzano Locsin ${ }^{2}$, Soichi Honda ${ }^{5}$ \\ ${ }^{1}$ Graduate School of Health Sciences, Tokushima University, Tokushima, Japan \\ ${ }^{2}$ Institute of Biomedical Sciences, Tokushima University, Tokushima, Japan \\ ${ }^{3}$ Department of Nursing, Faculty of Nursing, Shikoku University, Tokushima, Japan \\ ${ }^{4}$ Gifu College of Nursing, Gifu, Japan \\ ${ }^{5}$ Minami Hospital, Tokushima, Japan \\ Email: hirokos1014@outlook.jp
}

How to cite this paper: Sugimoto, H., Tanioka, T., Yasuhara, Y., Kurokawa, A., Sato, M., Ozawa, K., Locsin, R. and Honda, S. (2018) The Relationship among Chronic Disease, Feeling-for-Their-Age, Sleep Quality, Health-Related Quality of Life and Activities of Daily Living of Community-Dwelling Persons over 55 Years of Age. Open Journal of Psychiatry, 8, 20-34.

https://doi.org/10.4236/ojpsych.2018.81002

Received: September 29, 2017

Accepted: November 26, 2017

Published: November 29, 2017

Copyright $\odot 2018$ by authors and Scientific Research Publishing Inc. This work is licensed under the Creative Commons Attribution International License (CC BY 4.0).

http://creativecommons.org/licenses/by/4.0/

\section{Open Access}

\begin{abstract}
Japan's aging population rate is increasing and healthy life expectancy has decreases by 10 years shorter than average life expectancy. The aim of this study is to determine the relationship among chronic disease, sleep quality, health-related quality of life (HRQOL), and activities of daily living in people over 55 years old who live in the community. Subjects were 161 persons aged 57 to 90 years who were treated with chronic disease in the outpatient department of the A hospital. Exclusion criteria included patients with dementia, cancer and severe heart disease. The survey evaluation questionnaires included the Pittsburgh Sleep Quality Index (PSQI), HRQOL by Short-Form 8 Health Survey (SF-8), and activities of daily living. Variables associated with quality of sleep, HRQOL in univariate analysis with $\mathrm{p}<0.05$ were entered into multivariate analysis using logistic regression with a stepwise forward selection procedure to determine independent variables and their association with major causes. The logistic regression analysis was done using SPSS software and the post-hoc power of the study was estimated using $\mathrm{G}^{*}$ power. The level of significance was set at $\mathrm{p}<0.05$. The risk factor of poor sleep quality was because of history of cancer [odds ratio (OR): 3.53, 95\% confidence interval (CI): 1.06 - 11.77], and insomnia (OR: 3.25, 95\% CI: 1.55 - 6.79). The risk factors of poor physical HRQOL were motor disease (OR: 2.62, 95\% CI: 1.36 - 5.07), respiratory dis-
\end{abstract}


ease (OR: 3.24, 95\% CI: 1.27 - 8.26) and having pain (OR: 11.71, 95\% CI: 5.35 25.66). In addition, anemia was found to be a risk factor of poor mental HRQOL (OR: 4.87, 95\% CI: 1.11 - 21.33). The feeling-for-their-body-age (OR: 0.30, 95\% CI: 0.15-0.59) was as "younger than actual age" and advanced the risk factor of poor sleep quality. In addition, feeling-for-their-age (OR: 0.44, 95\% CI: 0.21 - 0.92) resulted in reduced risk factor of poor physical HRQOL. The risk factor of poor sleep quality was due to a patient with history of cancer. The factor for good sleep quality and the good factor for physical HRQOL were indications of feeling younger than the actual age.

\section{Keywords}

Elderly, Health-Related Quality of Life, Sleep Quality, Activities of Daily Living

\section{Introduction}

Japan's aging population rate is increasing [1], and average healthy life expectancy, and male healthy life expectancy are 9.13 years shorter than the average life expectancy; female healthy life expectancy is 12.68 years shorter than average life expectancy [2]. If people can promote their health and live well, their well-being even if they have some disease, might be able to maintain their quality of life (QOL) and extend their healthy life expectancy. Aged people tend to live with some chronic diseases [3]; therefore, it is important to describe the characteristics of those who are living a vivid life coping with chronic disease.

Sleep is a universal behavior, essential for humans to survive [4] and difficulties in initiating sleep are associated with mortality [5]. However, sleeping is one of the most important health issues for the elderly [6]. The sleep quality decreases with age [7] and the following changes occur. That is increase in daytime drowsiness, decrease in sleeping time, difficulty in getting to sleep, nocturnal awakening, sleep fragmentation, decrease in deep sleeps at stage 3 and 4 of non-REM sleep and the acceleration of circadian rhythm of becoming sleepy in the early evening and awakening in the early morning [8] [9]. Approximately, 33\% of the general population suffer from symptoms of insomnia [10]. The symptoms of lack of sleep and insomnia are related to the decrease in operating efficiency [11], the increases in the risks of mental disorders including depression [12], risk of death [13] [14], risk of falling [15] and a decrease in cognitive function [8] [16]. It is also determined that short-duration sleep and waking-up in the early morning are related to a strong sense of fatigue [17].

One of the causes of an abnormality of sleep in the elderly is the decrease in physical activities [18] [19] [20] [21]. Because the lack of physical activities, in particular, affects the role of autonomic nerve system inhibiting obesity and appetite and the activity of biomarker of metabolic system, it is suggested that this likely advances the aging process, leading to physical and brain disorders [22]. It is also reported that exercise improves the sleep quality and mental health [23] 
[24], and suggested that physical and social activities enhance memory and improve the quality of sleep [25]. In order for the elderly to live healthy lives, it is important to be active in the daytime and have a high sleep quality.

Similarly, it is reported that the elderly lose their remaining teeth with aging, and their intake of nourishment and chewing ability decrease [26] [27] [28]. Those who have less than 19 teeth and use no denture are in high risk of falling [29] and that chewing ability is related to problems with activities of daily living (ADL) [30], recognition function [31] and over-all HRQOL [32]. Although there are several reports concerning the relationship between chewing ability and QOL relating to health [33] [34], the relationship between chewing ability and the sleep quality has scarcely been studied.

In previous research, the Pittsburgh Sleep Quality Index (PSQI), the symptoms of sleep disturbance and the relationship among sleep problems including insomnia, activities of daily living and the existence or non-existence of chronic disease were found. It was reported that sleep disturbance is associated with various chronic diseases including depression [9] [35], heart diseases [9] [35] [36], arthritis [9] [35] [36]' lung diseases [35] [36], the problems of precognitive function [35] [37], body aches and pains [36] [37] and restriction in daily activities [9] [38]. Also, it was found that good-quality sleep was related to healthy HRQOL [38] [39]. Moreover, how to recognize their own heath conditions and the problems of sleep and sleep quality were addressed. In the case of those who felt they are not healthy, the sleep quality was significantly poor [39] [40], sleeping time was short [39]. This was found related to their daytime drowsiness [9].

Nevertheless, the relationship among sleep quality, activities of daily living and existence or non-existence of chronic disease, including physical and mental HRQOL, has not been examined enough focusing on the feeling-for-their-age and oral cavity function.

The aim of this study is to describe the relationship among chronic disease, sleep quality, HRQOL and activities of daily living of community-dwelling persons over 55 years of age.

\section{Methods}

\subsection{Subjects}

Two hundred fifty subjects were selected for this survey who were outpatients at A Hospital. Only 164 subjects consented with 161 of them between the ages of 57 to 90 years old and were on treatment for their chronic disease. Valid response rate was $98.2 \%$. These subjects met the following inclusion criteria: Ability to complete a questionnaire; and over 55 years old with chronic disease. Exclusion criteria included those with dementia, severe heart disease, and those under treatment for cancer disease.

\subsection{Study Period}

The research study was conducted from July 11, 2016 to January 4, 2017. 


\subsection{Measures}

The following questionnaire forms were administered to obtain the data for the study: The subjective sleep quality was evaluated using The Japanese version of the PSQI (PSQI-J) [41] [42]. The PSQI-J consists of seven components (sleep quality, sleep latency, sleep duration, habitual sleep efficiency, sleep disturbance, use of sleeping medications, and daytime dysfunction) including sleep quality measurements for the previous month [43]. For this study, the PSQI cut-off score of $\geq 6$ was set as an indication of poor sleep quality [44].

At the same time, the subject's HRQOL using the Medical Outcomes Study 8 -item Short Form Health Survey for Japanese was determined [45]. SF-8 was evaluated with 8 subscales which consists of "physical functioning (PF)", "role physical (RP)", "bodily pain (BP)", "general health (GH)", "vitality (VT)", "social functioning (SF)", "role emotional (RE)", and "mental health (MH)". These subscales were summarized as the "physical health component summary score (PCS)" and "mental health component summary score (MCS)" [45]. The PCS and MCS were calculated by weighting each SF-8 item using a norm-based scoring method given in the instrument guidelines in the national standard values determined from a large-scale survey data for the general Japanese population. The score higher than 50 points meant higher than the average of the Japanese citizens in 2007 in general. In this study, the scores above 50 points were considered indications of good HRQOL.

The items for ADL were based on previous research [9] [29] [30] [31] [35] [36] [37] [39] [40]. The 14 ADL items were the following: gender, age, whether they live alone or not, having pain or not, lifestyle habits (exercise, job, hobby, drowsiness in the daytime, daytime nap, smoking), chewing ability (hard, sticky, and soft food), and wearing false tooth. Chewing ability was determined as poor when it was hard to eat either hard, sticky or soft food items.

Feeling-for-their-age about their bodily functions was derived from questions on whether or not the subjects felt that their bodies were younger than their actual age. Similarly, the chronic disease names were collected from the subjects' respective electronic medical record. Some patients had multiple diseases.

For measuring the $\mathrm{ADL}$ and Chronic disease, the data were divided into at present or not at present. For the PSQI, data were divided into good or poor, and for SF-8 (PCS, and MCS) the data were divided into two groups; those 50 points or more, respectively. Variables associated with sleep quality, HRQOL in univariate analysis with $\mathrm{p}<0.05$ were entered into multivariate analysis using logistic regression with a stepwise forward selection procedure to determine independent variables, and identify variables associated with major causes.

The logistic regression analysis was done using IBM SPSS ver. 24.0. The level of significance was set at $\mathrm{p}<0.05$.

Post-hoc power analysis for a logistic regression was conducted using the statistical power analyses software: the G*Power (version 3.1) [46]. Sufficient sam- 
ple size using an alpha 0.05 , a power of 0.80 , one-tailed test, and the desired sample size was 157 based on the aforementioned assumptions.

\subsection{Ethical Considerations}

The study was approved by the Ethics Committee of Tokushima University Hospital (No. 2648) and of A Hospital, Tokushima, Japan.

The following issues were carefully explained to the patients orally and in writing. The purpose and content of the study, and the voluntary nature of participation; if they refused to participate they would not cause any disadvantages; and the freedom of agreeing or not agreeing with the findings of the study, or its use in presentations of the research, and the rights of anonymity and secure confidentiality. The patients included in the study provided written informed consents to participate.

\section{Results}

The subject's basic characteristics are shown in Table 1 . The mean age was 76.16 \pm 7.75 years (range: 57 - 90 years).

Table 1. Basic characteristics of the participants $(n=161)$.

\begin{tabular}{|c|c|c|c|c|c|c|}
\hline \multicolumn{2}{|l|}{ Survey Items } & Minimum & Maximum & Mean & \pm & $\mathrm{SD}$ \\
\hline \multicolumn{2}{|c|}{ PSQI: Pittsburgh Sleep Quality Index (points) } & 0.00 & 16.00 & 6.17 & \pm & 3.57 \\
\hline PSQI $\geq 6$ vs. $<6$ & 80 vs. 81 & & & & & \\
\hline \multicolumn{2}{|c|}{ PCS: Physical Component Summary (points) } & 17.83 & 61.76 & 46.56 & \pm & 8.65 \\
\hline PCS $\geq 50$ vs. $<50$ & 71 vs. 90 & & & & & \\
\hline \multicolumn{2}{|c|}{ MCS: Mental Component Summary (points) } & 31.89 & 66.66 & 52.63 & \pm & 6.07 \\
\hline MCS $\geq 50$ vs. $<50$ & 117 vs. 44 & & & & & \\
\hline \multirow[t]{6}{*}{ Age (years)* } & & 57.00 & 90.00 & 76.16 & \pm & 7.75 \\
\hline & & & & $\mathrm{n}$ & & $\%$ \\
\hline & $55-64$ & & & 15 & & 9.3 \\
\hline & $65-74$ & & & 53 & & 32.9 \\
\hline & $75-84$ & & & 65 & & 40.4 \\
\hline & $85-90$ & & & 28 & & 17.4 \\
\hline \multirow[t]{2}{*}{ Gender } & Male & & & 74 & & 46.0 \\
\hline & Female & & & 87 & & 54.0 \\
\hline \multirow[t]{6}{*}{ Job Type $(\mathrm{n}=49)$} & Office worker & & & 1 & & 2.0 \\
\hline & Agriculture & & & 12 & & 24.5 \\
\hline & Fishery & & & 16 & & 32.7 \\
\hline & Self-employed business & & & 1 & & 2.0 \\
\hline & Public employees & & & 2 & & 4.1 \\
\hline & Others & & & 17 & & 34.7 \\
\hline
\end{tabular}

Job type: It shows only employed people. ${ }^{*}$ In Japan, people over 65 years old can receive the old-age basic pension at the age of 65, if people have been covered under the National Pension and Employees' Pension Insurance Systems. There were 146 subjects among the 161 subjects who were 65 years old or older. 
Table 2 shows the relations among chronic disease, sleep quality, and PCS/ MCS. Poor sleep quality was associated with having diabetes (OR: 2.04, 95\% CI: 1.07 - 3.91), history of cancer (OR: $3.40,95 \%$ CI: $1.05-11.03$ ), and insomnia (OR: 3.19, 95\% CI: 1.54 - 6.62). The results of stepwise logistic analysis showed that poor sleep quality was associated with history of cancer (OR: $3.53,95 \% \mathrm{CI}$ : 1.06 - 11.77), and insomnia (OR: 3.25, 95\% CI: 1.55 - 6.79).

In the relations between PCS and chronic disease: motor disease (OR: 2.56, 95\% CI: 1.35 - 4.88), respiratory disease (OR: 3.14, 95\% CI: 1.26 - 7.82), and urological disease (OR: 2.06, 95\% CI: 1.01 - 4.21) were risk factors for poor physical HRQOL. Stepwise logistic analysis showed that motor disease (OR: 2.62, 95\% CI:

Table 2. Relationship among chronic disease, sleep quality, and physical/mental quality of life $(\mathrm{n}=161)$.

\begin{tabular}{|c|c|c|c|c|c|c|c|c|c|c|c|c|}
\hline \multirow{3}{*}{ Chronic disease } & \multicolumn{4}{|c|}{ PSQI $^{* 1}$} & \multicolumn{4}{|c|}{$\mathrm{PCS}^{* 2}$} & \multicolumn{4}{|c|}{$\mathrm{MCS}^{* 2}$} \\
\hline & \multicolumn{2}{|c|}{ PSQI $\geq 6$} & \multirow{2}{*}{$\begin{array}{c}\text { Univariate } \\
\text { OR }(95 \% \mathrm{CI})\end{array}$} & \multirow{2}{*}{$\begin{array}{l}\left.\text { Multivariate }^{a}\right) \\
\text { OR }(95 \% \mathrm{CI})\end{array}$} & \multicolumn{2}{|c|}{$\mathrm{PCS}<50$} & \multirow{2}{*}{$\begin{array}{c}\text { Univariate } \\
\text { OR }(95 \% \mathrm{CI})\end{array}$} & \multirow{2}{*}{$\begin{array}{l}\text { Multivariate }^{\mathrm{a})} \\
\text { OR }(95 \% \mathrm{CI})\end{array}$} & \multicolumn{2}{|c|}{$\mathrm{MCS}<50$} & \multirow{2}{*}{$\begin{array}{c}\text { Univariate } \\
\text { OR }(95 \% \mathrm{CI})\end{array}$} & \multirow{2}{*}{$\begin{array}{c}\text { Multivariate }^{\mathrm{a})} \\
\text { OR }(95 \% \mathrm{CI})\end{array}$} \\
\hline & $n$ & $\%$ & & & $n$ & $\%$ & & & $n$ & $\%$ & & \\
\hline Diabetes & 37 & 23.0 & $\underline{2.04(1.07-3.91)}$ & & 37 & 23.0 & $1.37(0.72-2.61)$ & & 15 & 9.3 & $0.80(0.39-1.65)$ & \\
\hline $\begin{array}{l}\text { Diseases related to } \\
\text { the brain }\end{array}$ & 16 & 9.9 & $1.59(0.69-3.68)$ & & 18 & 11.2 & $1.72(0.72-4.11)$ & & 7 & 4.3 & $0.92(0.36-2.35)$ & \\
\hline $\begin{array}{l}\text { Cardiovascular } \\
\text { disease }\end{array}$ & 35 & 21.7 & $1.02(0.55-1.91)$ & & 42 & 26.1 & $1.34(0.72-2.53)$ & & 16 & 9.9 & $0.67(0.33-1.36)$ & \\
\hline Hypertension & 64 & 39.8 & $1.40(0.67-2.93)$ & & 68 & 42.2 & $0.83(0.39-1.75)$ & & 33 & 20.5 & $0.86(0.38-1.93)$ & \\
\hline Dyslipidemia & 36 & 22.4 & $0.80(0.43-1.48)$ & & 37 & 23.0 & $0.54(0.29-1.02)$ & & 20 & 12.4 & $0.88(0.44-1.76)$ & \\
\hline Motor disease & 51 & 31.7 & $1.63(0.87-3.07)$ & & 61 & 37.9 & $\underline{2.56(1.35-4.88)}$ & $\frac{2.62}{(1.36-5.07)}$ & 27 & 16.8 & $1.23(0.60-2.49)$ & \\
\hline $\begin{array}{l}\text { Gastrointestinal } \\
\text { disease }\end{array}$ & 47 & 29.2 & $1.26(0.68-2.35)$ & & 54 & 33.5 & $1.46(0.78-2.73)$ & & 23 & 14.3 & $0.82(0.41-1.64)$ & \\
\hline Respiratory disease & 16 & 9.9 & $1.20(0.54-2.65)$ & & 23 & 14.3 & $\underline{3.14(1.26-7.82)}$ & $\frac{3.24}{(1.27-8.26)}$ & 6 & 3.7 & $0.61(0.23-1.62)$ & \\
\hline Urological disease & 24 & 14.9 & $1.08(0.55-2.13)$ & & 32 & 19.9 & $2.06(1.01-4.21)$ & & 10 & 6.2 & $0.64(0.28-1.42)$ & \\
\hline $\begin{array}{l}\text { Hepatobiliary and } \\
\text { pancreatic disease }\end{array}$ & 23 & 14.3 & $2.11(0.98-4.54)$ & & 22 & 13.7 & $1.32(0.62-2.81)$ & & 12 & 7.5 & $1.45(0.65-3.24)$ & \\
\hline Thyroid disease & 8 & 5.0 & $2.14(0.62-7.41)$ & & 5 & 3.1 & $0.54(0.16-1.77)$ & & 6 & 3.7 & $2.92(0.89-9.60)$ & \\
\hline $\begin{array}{l}\text { Disease related to } \\
\text { colon }\end{array}$ & 4 & 2.5 & $0.48(0.14-1.66)$ & & 6 & 3.7 & $0.77(0.24-2.51)$ & & 2 & 1.2 & $0.51(0.11-2.42)$ & \\
\hline $\begin{array}{l}\text { Disease related to } \\
\text { neurology }\end{array}$ & 11 & 6.8 & $1.46(0.55-3.83)$ & & 9 & 5.6 & $0.68(0.26-1.77)$ & & 3 & 1.9 & $0.46(0.13-1.67)$ & \\
\hline Anemia & 5 & 3.1 & $1.73(0.40-7.51)$ & & 3 & 1.9 & $0.46(0.11-1.97)$ & & 5 & 3.1 & $\underline{4.87(1.11-21.33)}$ & $\frac{4.87}{(1.11-21.33)}$ \\
\hline Dizziness & 15 & 9.3 & $1.85(0.76-4.50)$ & & 17 & 10.6 & $2.13(0.83-5.46)$ & & 4 & 2.5 & $0.49(0.16-1.51)$ & \\
\hline
\end{tabular}

a) A significant one in univariate was used as an explanatory variable for the stepwise logistic regression analysis in relation to poor PSQI, PCS and MCS. PSQI: Pittsburgh Sleep Quality Index; PCS: Physical Component Summary; MCS: Mental Component Summary; The number shows people who suffered from the disease. ${ }^{* 1}$ The score higher than 6 points means poor sleep quality. ${ }^{*}$ The score higher than 50 points means higher than the average of the Japanese citizens in 2007 in general. 
1.36 - 5.07) and respiratory disease (OR: 3.24, 95\% CI: 1.27 - 8.26) were related poor physical HRQOL. In addition, anemia was a risk factor of poor mental health HRQOL (OR: 4.87, 95\% CI: 1.11 - 21.33).

Table 3 shows relations among basic characteristics, lifestyle habits, feelingfor-their-age, sleep quality and PCS/MCS. Being a female (OR: 2.20, 95\% CI: 1.17 4.14) was a risk factor for poor sleep quality.

Table 3. Relationship among basic characteristics, lifestyle habits, feeling of age, sleep quality and physical/mental quality of life (n $=161)$.

\begin{tabular}{|c|c|c|c|c|c|c|c|c|c|c|c|c|c|}
\hline \multirow{3}{*}{ Survey items } & \multirow{3}{*}{ Response } & \multicolumn{4}{|c|}{$\mathrm{PSQI}^{*_{1}}$} & \multicolumn{4}{|c|}{$\mathrm{PCS}^{* 2}$} & \multicolumn{4}{|c|}{$\mathrm{MCS}^{* 2}$} \\
\hline & & \multicolumn{2}{|c|}{$\mathrm{PSQI} \geq 6$} & \multirow{2}{*}{$\begin{array}{c}\text { Univariate } \\
\text { OR }(95 \% \mathrm{CI})\end{array}$} & \multirow{2}{*}{$\begin{array}{c}\text { Multivariate }^{\mathrm{a})} \\
\text { OR }(95 \% \mathrm{CI})\end{array}$} & \multicolumn{2}{|c|}{$\mathrm{PCS}<50$} & \multirow{2}{*}{$\begin{array}{c}\text { Univariate } \\
\text { OR }(95 \% \mathrm{CI})\end{array}$} & \multirow{2}{*}{$\begin{array}{l}\text { Multivariate }^{\mathrm{a})} \\
\mathrm{OR}(95 \% \mathrm{CI})\end{array}$} & \multicolumn{2}{|c|}{$\mathrm{MCS}<50$} & \multirow{2}{*}{$\begin{array}{c}\text { Univariate } \\
\text { OR }(95 \% \mathrm{CI})\end{array}$} & \multirow{2}{*}{$\frac{\text { Multivariate }^{\mathrm{a}}}{\text { OR }(95 \% \mathrm{CI})}$} \\
\hline & & $\mathrm{n}$ & $\%$ & & & $\mathrm{n}$ & $\%$ & & & $\mathrm{n}$ & $\%$ & & \\
\hline Gender & Female & 51 & 31.7 & $2.20(1.17-4.14)$ & & 51 & 31.7 & $1.27(0.68-2.38)$ & & 24 & 14.9 & $1.03(0.51-2.06)$ & \\
\hline $\begin{array}{l}\text { Living with } \\
\text { family. }\end{array}$ & $\begin{array}{l}\text { I live with my } \\
\text { family. }\end{array}$ & 62 & 38.5 & $0.72(0.33-1.60)$ & & 69 & 42.9 & $0.60(0.27-1.35)$ & & 34 & 21.1 & $0.79(0.34-1.83)$ & \\
\hline $\begin{array}{l}\text { Living with } \\
\text { spouse. }\end{array}$ & $\begin{array}{l}\text { I live with } \\
\text { spouse. }\end{array}$ & 47 & 29.2 & $0.84(0.45-1.58)$ & & 53 & 32.3 & $0.74(0.39-1.41)$ & & 27 & 16.8 & $1.03(0.51-2.10)$ & \\
\hline Pain & I have a pain. & 39 & 24.2 & $1.19(0.64-2.21)$ & & 63 & 39.1 & $\underline{11.47(5.33-24.71)}$ & $\frac{11.71}{(5.35-25.66)}$ & 21 & 13.0 & $1.07(0.53-2.13)$ & \\
\hline Exercise & $\begin{array}{l}\text { I exercise } \\
\text { habit. }\end{array}$ & 68 & 42.2 & $0.89(0.37-2.16)$ & & 74 & 46.0 & $0.51(0.20-1.31)$ & & 38 & 23.6 & $1.08(0.40-2.94)$ & \\
\hline Job & I have a job. & 21 & 13.0 & $0.67(0.34-1.33)$ & & 25 & 15.5 & $0.75(0.38-1.48)$ & & 11 & 6.8 & $0.69(0.32-1.52)$ & \\
\hline Hobby & I have a hobby. & 57 & 34.2 & $0.87(0.44-1.72)$ & & 61 & 37.9 & $0.77(0.39-1.53)$ & & 27 & 16.8 & $0.57(0.28-1.19)$ & \\
\hline $\begin{array}{l}\text { Drowsiness } \\
\text { in the } \\
\text { daytime }\end{array}$ & $\begin{array}{l}\text { I have a } \\
\text { drowsiness in } \\
\text { the daytime. }\end{array}$ & 52 & 32.3 & $1.15(0.61-2.19)$ & & 59 & 36.6 & $1.24(0.65-2.36)$ & & 29 & 18.0 & $1.17(0.56-2.41)$ & \\
\hline Daytime nap & I take a nap. & 45 & 28.0 & $1.03(0.55-1.92)$ & & 52 & 32.3 & $1.19(0.64-2.22)$ & & 24 & 14.9 & $0.93(0.46-1.86)$ & \\
\hline $\begin{array}{l}\text { Age of } \\
\text { feeling }\end{array}$ & $\begin{array}{l}\text { I feel I am } \\
\text { young feeling. }\end{array}$ & 30 & 18.6 & $\underline{0.41(0.22-0.78)}$ & & 36 & 22.4 & $\underline{0.46(0.24-0.87)}$ & $\begin{array}{c}\frac{0.44}{(0.21-0.92)} \\
\end{array}$ & 18 & 11.2 & $0.66(0.33-1.33)$ & \\
\hline Age of body & $\begin{array}{l}\text { I feel I am } \\
\text { young body. }\end{array}$ & 18 & 11.2 & $\underline{0.30(0.15-0.59)}$ & $\frac{0.30}{(0.15-0.59)}$ & 28 & 17.4 & $0.62(0.32-1.18)$ & & 12 & 7.5 & $0.58(0.27-1.24)$ & \\
\hline $\begin{array}{l}\text { Smoking } \\
\text { history }\end{array}$ & $\begin{array}{l}\text { I have a } \\
\text { smoking } \\
\text { history. }\end{array}$ & 19 & 11.8 & $0.53(0.27-1.05)$ & & 29 & 18.0 & $1.21(0.61-2.39)$ & & 11 & 6.8 & $0.69(0.32-1.52)$ & \\
\hline Smoking & I have a smoke. & 4 & 2.5 & $0.42(0.12-1.43)$ & & 8 & 5.0 & $1.29(0.40-4.12)$ & & 3 & 1.9 & $0.78(0.21-2.99)$ & \\
\hline $\begin{array}{l}\text { Chewing } \\
\text { hard food }\end{array}$ & $\begin{array}{l}\text { I can't bite } \\
\text { hard food. }\end{array}$ & 27 & 16.8 & $1.21(0.62-2.35)$ & & 31 & 19.3 & $1.34(0.68-2.63)$ & & 15 & 9.3 & $1.16(0.56-2.43)$ & \\
\hline $\begin{array}{l}\text { Chewing } \\
\text { sticky food }\end{array}$ & $\begin{array}{l}\text { I can't bite } \\
\text { sticky food. }\end{array}$ & 22 & 13.7 & $1.82(0.85-3.87)$ & & 20 & 12.4 & $0.98(0.47-2.07)$ & & 11 & 6.8 & $1.23(0.54-2.77)$ & \\
\hline $\begin{array}{l}\text { Chewing soft } \\
\text { food }\end{array}$ & $\begin{array}{l}\text { t I can't bite soft } \\
\text { food. }\end{array}$ & 3 & 1.9 & - & & 2 & 1.2 & $1.60(0.14-17.91)$ & & 0 & 0.0 & - & \\
\hline $\begin{array}{l}\text { Chewing } \\
\text { ability }\end{array}$ & $\begin{array}{l}\text { Biting ability is } \\
\text { bad. }\end{array}$ & 39 & 24.2 & $1.80(0.96-3.39)$ & & 38 & 23.6 & $1.06(0.56-1.99)$ & & 20 & 12.4 & $1.24(0.62-2.50)$ & \\
\hline False tooth & $\begin{array}{l}\text { I wear false } \\
\text { tooth. }\end{array}$ & 48 & 29.8 & $1.39(0.75-2.60)$ & & 54 & 33.5 & $1.46(0.78-2.73)$ & & 24 & 14.9 & $0.93(0.46-1.86)$ & \\
\hline
\end{tabular}

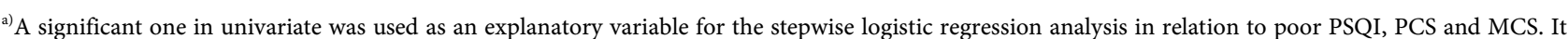
shows the number of respondents who answered "Yes" to each question. PSQI: Pittsburgh Sleep Quality Index; PCS: Physical Component Summary; MCS: Mental Component Summary; ${ }^{* 1}$ The score higher than 6 points means poor sleep quality. ${ }^{{ }^{2}}$ The score higher than 50 points means higher than the average of the Japanese citizens in 2007 in general. 
In contrast, the age of those who felt young (OR: $0.41,95 \%$ CI: $0.22-0.78$ ) and the age of those who felt that their bodies were younger than their actual age (OR: 0.30, 95\% CI: 0.15 - 0.59), were found to show a reduction as a risk factor for poor sleep quality. In the stepwise logistic analysis, it was shown that the feeling-for-their-body-age (OR: 0.30, 95\% CI: 0.15 - 0.59) as younger than actual age indicated a reduction as a risk factor of poor sleep quality.

However, in the relation among PCS, basic characteristics, lifestyle habits and feeling-for-their-age: physical pain was found to be a risk factor (OR: 11.47, 95\% CI: 5.33 - 24.71) for poor physical HRQOL, in contrast to those who felt about their age as younger than their actual age which showed a reduced risk factor (OR: 0.46, 95\% CI: 0.24 - 0.87). In addition, the stepwise analysis results showed that physical pain (OR: 11.71, 95\% CI: 5.35 - 25.66) was a risk factor for poor physical HRQOL, while feelings about their age as younger than actual age (OR: $0.44,95 \%$ CI: $0.21-0.92)$ indicated a reduction as a risk factor for poor physical HRQOL.

\section{Discussion}

In this research, it was found that sleep quality was affected by chronic disease such as cancer.

Sleep disturbance is a common symptom among patients with cancer [47] [48], and the pain caused by cancer [49], the use of palliative drugs for the treatment and the fatigue caused by surgery, chemotherapy, immunotherapy and irradiation therapy were related to effects of sleep disturbance. It was reported that the insomnia of patients with cancer occurs in relation to depression and anxiety [50]. However, in this study, because the subjects were not under cancer treatment, this was an exclusion criterion. It is highly unlikely that the treatment of cancer affected the subjects' sleep quality. Nevertheless, the possibility was considered that the mental condition caused by anxiety toward cancer recurrence and the aftermath of cancer treatment, that it might partially worsen the sleep quality.

However, there a report was found that cancer incidence has no relationship between the symptoms of insomnia, including difficulty in getting to sleep, nocturnal awakening and sleep problems including short sleep and daytime drowsiness [35], so that there is room for further research. Nevertheless, insomnia was found to be causes of poor sleep quality.

It is reported that the PSQI can distinguish the patients with primary insomnia in comparison with healthy subjects [51]. Because it can detect the sleep quality and the symptom of sleep disturbance [43], PSQI is a measure with good sensitivity. However, because PSQI is for the subjective evaluation of sleep quality, the result may possibly be different from the actual physical condition. In this situation, it is also important to objectively confirm whether the patient actually has been getting enough sleep by using the combination of actigraphy and heart rate variability analysis in the future [52]. 
Although no relationship between the sleep quality and other chronic diseases was observed, it was reported that poor control of blood glucose in type 2 diabetes cases could be a risk factor in the reduction of the sleep quality [53]. Similarly, heart diseases are risk factors with sleep durations of shorter than 6 hours, difficulty in getting to sleep and nocturnal and early morning awakening [9].

There is no relation between diabetes and the sleep quality [37]. The result of this research supports the latter report.

Regarding the relationship among the ADL, feeling-for-their-age and sleep quality, it is reported that feeling that feelings about one's age as younger than the actual age can favorably affect the sleep quality. It is reported that the sleep quality of the elderly who feel healthy is better [40].

Sustaining everyday customs of community elderly activities is related to decreased insomnia [54]. The subjects of this study were persons 55 years or older and are living in the community while suffering from chronic disease. They were happy with their present physical condition rather than thinking that their physical condition is appropriate only for their age, and that their self-efficacy made them feel young. It is highly possible that these thoughtful concerns favorably affected their sleep quality. In researches for the future, it is critical to investigate the values and histories of the lives of the subjects of this survey, their connection with others around them, and continue to survey the reasons for feeling younger than their actual age.

However, no other relationships with sleep quality were found with the other survey items.

It is reported that insomnia is often found in women [36] and the sleep quality is worse than in men [37]. However, this study did not clearly show the relationship between gender and the sleep quality, although it is reported that there is a relationship between insomnia and bodily pain [35] [36], it was not clarified in this study.

Regarding the relationship between PCS and chronic disease, the existence of motor system disease and respiratory disease was a factor lowering physical HRQOL.

It is said that the QOL of the patients with chronic obstructive pulmonary disease (COPD) becomes remarkably worse as it becomes more serious [55] [56]. In this research, they were analyzed as the patients with respiratory disease, not by diagnostic name, so that the influence by detailed state of disease was not cleared, but the existence of respiratory disease was considered a factor to lower physical HRQOL.

Feeling younger than actual age was a good factor for high physical HRQOL. The factor for feeling younger than their actual age has not been made clear. It is possible that those who still feel young do not take small physical problems in a negative way. Having less physical problems, comparing to those of the same generation, may make them feel younger. However, the relationship between whether they feel younger than their actual age and HRQOL could not be found 
in the previous research.

Anemia was a factor for lowering mental HRQOL. It is reported that anemia was a factor for lowering HRQOL affecting the physical function and activities of adolescents with chronic liver disease and influence on their parents [57]. It is reported that the treatment of anemia (Epoetin after therapy) for the patients who were receiving adjuvant chemotherapy for cancer or the combination therapy of interferon alfa (IFN) and ribavirin (RBV) for hepatitis C can improve QOL by improving the level of hemoglobin [58] [59]. From the above, it is considered that the diseases accompanied by anemia and the side effects of therapy lower mental HRQOL. However, it could not be clarified the relationship of those from the result of this research.

\section{Limitations}

In this research, the relationship between the duration of treatment, test value and risk factors of chronic diseases were not analyzed. It is a limitation of this research that the number of subjects was small. Regarding the relationship between insomnia and PSQI, because PSQI is for the detection of the symptoms of sleep disturbance, it was presented as a positive control. Similarly, it is considered that because bodily pain was included as a subscale of SF-8, there was bodily pain as a risk factor of physical HRQOL.

The relationship between research participants feeling younger than their actual age and the activities of daily living enhancing the sleep quality and living was not clarified. It is required to investigate the background where people can feel young physically and mentally and their living activities in detail in future research.

\section{Conclusion}

The risk factor of poor sleep quality was found to be on the subjects' history of having cancer. The factor for good sleep quality was about the subjects' feelingfor-their-age, in that, because they felt younger physically, they were able to sleep better. The good factor for physical HRQOL was the subjects' feeling of being younger than their actual age. Therefore, medical staff should carefully observe and support patients' sleep quality of those having a history of cancer treatment. In addition, medical staff has to focus on patients who are younger regarding their "feeling-for-their-age" in order to improve good sleep quality and HRQOL.

\section{Acknowledgements}

The authors would like to express their gratitude and deep appreciation to the subjects of this study, Dr. Yoshihiro Suzuki and all the staff at the Minami Hospital who have helped in many ways. Further gratitude is expressed for Professor Tetsuya Tanioka, Associate Professor Yuko Yasuhara, and the members of the Department of Nursing Outcomes Management Laboratory for their unending assistance in this endeavor. 


\section{References}

[1] Ministry of Health, Labor and Welfare: Japan (2012) About the Outlook for Japan's Population Composition. (In Japanese)

http://www.mhlw.go.jp/seisakunitsuite/bunya/hukushi_kaigo/kaigo_koureisha/chii ki-houkatsu/dl/link1-1.pdf

[2] Ministry of Health, Labor and Welfare: Japan (2012) Compare Average Lifespan with Healthy Life. (In Japanese)

http://www.mhlw.go.jp/bunya/kenkou/dl/chiiki-gyousei_03_02.pdf

[3] Ministry of Health, Labor and Welfare: Japan (2014) The 2014 Briefing on the Survey of Patients. (In Japanese) http://www.mhlw.go.jp/toukei/saikin/hw/kanja/14/

[4] Rechtschaffen, A. (1998) Current Perspectives on the Function of Sleep. Perspectives in Biology and Medicine, 41, 359-390. https://doi.org/10.1353/pbm.1998.0051

[5] Lallukka, T., Podlipskytè, A., Sivertsen, B., Andruškienė, J., Varoneckas, G., Lahelma, E., Ursin, R., Tell, G.S. and Rahkonen, O. (2016) Insomnia Symptoms and Mortality: A Register-Linked Study among Women and Men from Finland, Norway and Lithuania. Journal of Sleep Research, 25, 96-103. https://doi.org/10.1111/jsr.12343

[6] Doi, Y., Minowa, M., Okawa, M. and Uchiyama, M. (2000) Prevalence of Sleep Disturbance and Hypnotic Medication Use in Relation to Sociodemographic Factors in the General Japanese Adult Population. Journal of Epidemiology, 10, 79-86. https://doi.org/10.2188/jea.10.79

[7] Buysse, D.J., Reynolds, C.F., Monk, T.H., Hoch, C.H., Yeager, A.L. and Kupfer, D.J. (1991) Quantification of Subjective Sleep Quality in Healthy Elderly Men and Women Using the Pittsburgh Sleep Quality Index (PSQI). Sleep, 14, 331-338.

[8] Neubauer, D.N. (1999) Sleep Problems in the Elderly. American Family Physician, 59, 2551-2560. http://www.aafp.org/afp/1999/0501/p2551.html

[9] Newman, A.B., Enright, P.L., Manolio, T.A., Haponik, E.F. and Wahl, P.W. (1997) Sleep Disturbance, Psychosocial Correlates, and Cardiovascular Disease in 5201 Older Adults: The Cardiovascular Health Study. Journal of the American Geriatrics Society, 45, 1-7. https://doi.org/10.1111/j.1532-5415.1997.tb00970.x

[10] Ohayon, M.M. (2002) Epidemiology of Insomnia: What We Know and What We Still Need to Learn. Sleep Medicine Reviews, 6, 97-111.

https://doi.org/10.1053/smrv.2002.0186

[11] Belenky, G., Wesensten, N.J., Thorne, D.R., Thomas, M.L., Sing, H.C., Redmond, D.P., Russo, M.B. and Balkin, T.J. (2003) Patterns of Performance Degradation and Restoration during Sleep Restriction and Subsequent Recovery: A Sleep Dose-Response Study. Journal of Sleep Research, 12, 1-12. https://doi.org/10.1046/j.1365-2869.2003.00337.x

[12] Ford, D.E. and Kamerow, D.B. (1989) Epidemiologic Study of Sleep Disturbances and Psychiatric Disorders. An Opportunity for Prevention? JAMA, 262, 1479-1484. https://doi.org/10.1001/jama.1989.03430110069030

[13] Tamakoshi, A., Ohno, Y. and JACC Study Group (2004) Self-Reported Sleep Duration as a Predictor of All-Cause Mortality: Results from the JACC Study, Japan. Sleep, 27, 51-54.

[14] Chien, K.L., Chen, P.C., Hsu, H.C., Su, T.C., Sung, F.C., Chen, M.F. and Lee, Y.T. (2010) Habitual Sleep Duration and Insomnia and the Risk of Cardiovascular Events and All-Cause Death: Report from a Community-Based Cohort. Sleep, 33, 177-184. https://www.ncbi.nlm.nih.gov/pmc/articles/PMC2817905/ https://doi.org/10.1093/sleep/33.2.177 
[15] Brassington, G.S., King, A.C. and Bliwise, D.L. (2000) Sleep Problems as a Risk Factor for Falls in a Sample of Community-Dwelling Adults Aged 64-99 Years. Journal of the American Geriatrics Society, 48, 1234-1240. https://doi.org/10.1111/j.1532-5415.2000.tb02596.x

[16] Cricco, M., Simonsick, E.M. and Foley, D.J. (2011) The Impact of Insomnia on Cognitive Functioning in Older Adults. Journal of the American Geriatrics Society, 49, 1185-1189. https://doi.org/10.1046/j.1532-5415.2001.49235.x

[17] Goldman, S.E., Ancoli-Israel, S., Boudreau, R., Cauley, J.A., Hall, M., Stone, K.L., Rubin, S.M., Satterfield, S., Simonsick, E.M., Newman, A.B. and Health, Aging and Body Composition Study (2008) Sleep Problems and Associated Daytime Fatigue in Community-Dwelling Older Individuals. The Journals of Gerontology. Series A, Biological Sciences and Medical Sciences, 63, 1069-1075. https://doi.org/10.1093/gerona/63.10.1069

[18] Reid, K.J., Baron, K.G., Lu, B., Naylor, E., Wolfe, L. and Zee, P.C. (2010) Aerobic Exercise Improves Self-Reported Sleep and Quality of Life in Older Adults with Insomnia. Sleep Medicine, 11, 934-940.

[19] Goldman, S.E., Stone, K.L., Ancoli-Israel, S., Blackwell, T., Ewing, S.K., Boudreau, R., Cauley, J.A., Hall, M., Matthews, K.A. and Newman, A.B. (2007) Poor Sleep Is Associated with Poorer Physical Performance and Greater Functional Limitations in Older Women. Sleep, 30, 1317-1324.

https://www.ncbi.nlm.nih.gov/pmc/articles/PMC2266278/ https://doi.org/10.1093/sleep/30.10.1317

[20] Chasens, E.R., Sereika, S.M. and Weaver, T.E. (2007) Daytime Sleepiness, Exercise, and Physical Function in Older Adults. Journal of Sleep Research, 16, 60-65. https://doi.org/10.1111/j.1365-2869.2007.00576.x

[21] Malinowska, K.B., Okura, M., Ogita, M., Yamamoto, M., Nakai, T., Numata, T., Tsuboyama, T. and Arai, H. (2016) Effect of Self-Reported Quality of Sleep on Mobility in Older Adults. Geriatrics \& Gerontology International, 16, 266-271. https://doi.org/10.1111/ggi.12468

[22] Moritani, T. and Akamatsu, Y. (2015) Effect of Exercise and Nutrition upon Lifestyle-Related Disease and Cognitive Function. Journal of Nutritional Science and Vitaminology, 61, 122-124. https://doi.org/10.3177/jnsv.61.S122

[23] Tanaka, H. and Shirakawa, S. (2004) Sleep Health, Lifestyle and Mental Health in the Japanese Elderly: Ensuring Sleep to Promote a Healthy Brain and Mind. Journal of Psychosomatic Research, 56, 465-477.

[24] Tanaka, H., Taira, K., Arakawa, M., Toguti, H., Urasaki, C., Yamamoto, Y., Uezu, E., Hori, T. and Shirakawa, S. (2001) Effects of Short Nap and Exercise on Elderly People having Difficulty in Sleeping. Psychiatry and Clinical Neurosciences, 55, 173-174. https://doi.org/10.1046/j.1440-1819.2001.00813.x

[25] Naylor, E., Penev, P.D., Orbeta, L., Janssen, I., Ortiz, R., Colecchia, E.F., Keng, M., Finkel, S. and Zee, P.C. (2000) Daily Social and Physical Activity Increases Slow-Wave Sleep and Day-Time Neuropsychological Performance in the Elderly. Sleep, 23, 87-95. https://doi.org/10.1093/sleep/23.1.1f

[26] Ministry of Health, Labor and Welfare: Japan (2016) Result of the Dental Disease Survey. (In Japanese) http://www.mhlw.go.jp/toukei/list/dl/62-28-02.pdf

[27] Ministry of Health, Labor and Welfare: Japan (2015) National Health and Nutrition Survey. (In Japanese)

http://www.mhlw.go.jp/file/04-Houdouhappyou-10904750-Kenkoukyoku-Gantaisa kukenkouzoushinka/kekkagaiyou.pdf 
[28] Wakai, K., Naito, M., Naito, T., Kojima, M., Nakagaki, H., Umemura, O., Yokota, M., Hanada, N. and Kawamura, T. (2010) Tooth Loss and Intakes of Nutrients and Foods: A Nationwide Survey of Japanese Dentists. Community Dentistry and Oral Epidemiology, 38, 43-49. https://doi.org/10.1111/j.1600-0528.2009.00512.x

[29] Yamamoto, T., Kondo, K., Misawa, J., Hirai, H., Nakade, M., Aida, J., Kondo, N., Kawachi, I. and Hirata, Y. (2012) Dental Status and Incident Falls among Older Japanese: A Prospective Cohort Study. BMJ Open, 2, e001262. https://doi.org/10.1136/bmjopen-2012-001262

[30] Takata, Y., Ansai, T., Awano, S., Sonoki, K., Fukuhara, M., Wakisaka, M. and Takehara, T. (2004) Activities of Daily Living and Chewing Ability in an 80-Year-Old Population. Oral Diseases, 10, 365-368. https://doi.org/10.1111/j.1601-0825.2004.01047.x

[31] Lexomboon, D., Trulsson, M., Wårdh, I. and Parker, M.G. (2012) Chewing Ability and Tooth Loss: Association with Cognitive Impairment in an Elderly Population Study. Journal of the American Geriatrics Society, 60, 1951-1956. https://doi.org/10.1111/j.1532-5415.2012.04154.x

[32] Inukai, M., John, M.T., Igarashi, Y. and Baba, K. (2010) Association between Perceived Chewing Ability and Oral Health-Related Quality of Life in Partially Dentate Patients. Health and Quality of Life Outcomes, 8, 118. https://doi.org/10.1186/1477-7525-8-118

[33] Miura, H., Hara, S., Yamasaki, K. and Usui, Y. (2012) Relationship between Chewing and Swallowing Functions and Health-Related Quality of Life. InTech Open, 1-14.

[34] Brennan, D.S., Spencer, A.J. and Roberts-Thomson, K.F. (2008) Tooth Loss, Chewing Ability and Quality of Life. Quality of Life Research, 17, 227-235. https://doi.org/10.1007/s11136-007-9293-2

[35] Foley, D., Ancoli-Israel, S. and Britz, P. (2004) Sleep Disturbances and Chronic Disease in Older Adults: Results of the 2003 National Sleep Foundation Sleep in America Survey. Journal of Psychosomatic Research, 56, 497-502.

[36] Chiou, J.H., Chen, H.C., Chen, K.H. and Chou, P. (2016) Correlates of Self-Report Chronic Insomnia Disorders with 1-6 Month and 6-Month Durations in Home-Dwelling Urban Older Adults-The Shih-Pai Sleep Study in Taiwan: A Cross-Sectional Community Study. BMC Geriatrics, 16, 119. https://doi.org/10.1186/s12877-016-0290-6

[37] Quan, S.A., Li, Y.C., Li, W.J., Li, Y., Jeong, J.Y. and Kim, D.H. (2016) Gender Differences in Sleep Disturbance among Elderly Koreans: Hallym Aging Study. Journal of Korean Medical Science, 31, 1689-1695. https://doi.org/10.3346/jkms.2016.31.11.1689

[38] Li, J., Yao, Y.S., Dong, Q., Dong, Y.H., Liu, J.J., Yang, L.S. and Huang, F. (2013) Characterization and Factors Associated with Sleep Quality among Rural Elderly in China. Archives of Gerontology and Geriatrics, 56, 237-243.

[39] Lo, C.M. and Lee, P.H. (2012) Prevalence and Impacts of Poor Sleep on Quality of Life and Associated Factors of Good Sleepers in a Sample of Older Chinese Adults. Health and Quality of Life Outcomes, 10, 72. https://doi.org/10.1186/1477-7525-10-72

[40] Daglar, G., Pinar, S.E., Sabanciogullari, S. and Kav, S. (2014) Sleep Quality in the Elderly Either Living at Home or in a Nursing Home. Australian Journal of Advanced Nursing, 31, 6-13.

[41] Doi, Y., Minowa, M., Uchiyama, M. and Okawa, M. (1998) Development of the Pittsburgh Sleep Quality Index Japanese Version. Japanese Journal of Psychiatric Treatment, 13, 755-763. (In Japanese) 
[42] Doi, Y., Minowa, M., Uchiyama, M., Okawa, M., Kim, K., Shibui, K. and Kamei, Y. (2000) Psychometric Assessment of Subjective Sleep Quality using the Japanese Version of the Pittsburgh Sleep Quality Index (PSQI-J) in Psychiatric Disordered and Control Subjects. Psychiatry Research, 97, 165-172.

[43] Buysse, D.J., Reynolds, C.F., Monk, T.H., Berman, S.R. and Kupfer, D.J. (1989) The Pittsburgh Sleep Quality Index: A New Instrument for Psychiatric Practice and Research. Psychiatry Research, 28, 193-213.

[44] Alsaadi, S.M., McAuley, J.H., Hush, J.M., Bartlett, D.J., Henschke, N., Grunstein, R.R. and Maher, C.G. (2013) Detecting Insomnia in Patients with Low Back Pain: Accuracy of Four Self-Report Sleep Measures. BMC Musculoskeletal Disorders, 14, 196. https://doi.org/10.1186/1471-2474-14-196

[45] Fukuhara, S. and Suzukamo, Y. (2004) Manual of the SF-8 Japanese Version. Institute for Health Outcome and Process Evaluation Research, Kyoto.

[46] Faul, F., Erdfelder, E., Lang, A.-G. and Buchner, A. (2007) G Power 3: A Flexible Statistical Power Analysis Program for the Social, Behavioral, and Biomedical Sciences. Behavior Research Methods, 39, 175-191.

https://doi.org/10.3758/BF03193146

[47] Derogatis, L.R., Feldstein, M., Morrow, G., Schmale, A., Schmitt, M., Gates, C., Murawski, B., Holland, J., Penman, D., Melisaratos, N., Enelow, A.J. and Adler, L.M. (1979) A Survey of Psychotropic Drug Prescriptions in an Oncology Population. Cancer, 44, 1919-1929.

https://doi.org/10.1002/1097-0142(197911)44:5<1919::AID-CNCR2820440555>3.0. $\mathrm{CO} ; 2-\mathrm{T}$

[48] Miaskowski, C. and Lee, K.A. (1999) Pain, Fatigue, and Sleep Disturbances in Oncology Outpatients Receiving Radiation Therapy for Bone Metastasis: A Pilot Study. Journal of Pain and Symptom Management, 17, 320-332.

[49] Dorrepaal, K.L., Aaronson, N.K. and van Dam, F.S. (1989) Pain Experience and Pain Management among Hospitalized Cancer Patients. A Clinical Study. Cancer, 63, 593-598. https://doi.org/10.1002/1097-0142(19890201)63:3<593::AID-CNCR2820630332>3.0 .CO;2-5

[50] Theobald, D.E. (2004) Cancer Pain, Fatigue, Distress, and Insomnia in Cancer Patients. Clinical Cornerstone, 6, S15-S21.

[51] Backhaus, J., Junghanns, K., Broocks, A., Riemann, D. and Hohagen, F. (2002) Test-Retest Reliability and Validity of the Pittsburgh Sleep Quality Index in Primary Insomnia. Journal of Psychosomatic Research, 53, 737-740.

[52] Fuji, S., Tanioka, T., Yasuhara, Y., Sato, M., Saito, K., Purnell, M., Locsin, R. and Yasui, T. (2016) Characteristic Autonomic Nervous Activity of Institutionalized Elders with Dementia. Open Journal of Psychiatry, 6, 34-49.

https://doi.org/10.4236/ojpsych.2016.61004

[53] Tsai, Y.W., Kann, N.H., Tung, T.H., Chao, Y.J., Lin, C.J., Chang, K.C., Chang, S.S. and Chen, J.Y. (2012) Impact of Subjective Sleep Quality on Glycemic Control in Type 2 Diabetes Mellitus. Family Practice, 29, 30-35.

https://doi.org/10.1093/fampra/cmr041

[54] Zisberg, A., Gur-Yaish, N. and Shochat, T. (2010) Contribution of Routine to Sleep Quality in Community Elderly. Sleep, 33, 509-514. https://doi.org/10.1093/sleep/33.4.509

[55] Zamzam, M.A., Azab, N.Y., El Wahsh, R.A., RagabbEnas, A.Z. and Allamc, E.M. (2012) Quality of Life in COPD Patients. Egyptian Journal of Chest Diseases and Tuberculosis, 61, 281-289. 
[56] Kendrova, L., Mikulakona, W., Nechvatal, P., Homzova, P., Gajdos, M. and Čuj, J. (2015) Quality of Life Patients with Chronic Obstructive Palmonaly Disease in Slovakia. Hrvatska revija za rehabilitacijska istraživanja, 51, 57-63.

[57] Gerson, A., Hwang, W., Fiorenza, J., Barth, K., Kaskel, F., Weiss, L., Zelikovsky, N., Fivush, B. and Furth, S. (2004) Anemia and Health-Related Quality of Life in Adolescents with Chronic Kidney Disease. American Journal of Kidney Diseases, 44, 1017-1023. https://doi.org/10.1053/j.ajkd.2004.08.024

[58] Gabrilove, J.L., Cleeland, C.S., Livingston, R.B., Sarokhan, B., Winer, E. and Einhorn, L.H. (2001) Clinical Evaluation of Once-Weekly Dosing of Epoetin Alfa in Chemotherapy Patients: Improvements in Hemoglobin and Quality of Life Are Similar to Three-Times-Weekly Dosing. Journal of Clinical Oncology, 19, 2875-2882. https://doi.org/10.1200/JCO.2001.19.11.2875

[59] Pockros, P.J., Shiffman, M.L., Schiff, E.R., Sulkowski, M.S., Younossi, Z., Dieterich, D.T., Wright, T.L., Mody S.H., Tang, K.L., Goon, B.L., Bowers, P.J., Leitz, G., Afdhal, N.H. and PROACTIVE Study Group (2004) Epoetin Alfa Improves Quality of Life in Anemic HCV-Infected Patients Receiving Combination Therapy. Hepatolo$g y$, 40, 1450-1458. https://doi.org/10.1002/hep.20482 